\title{
Environmental production of fashion colors from natural dyes
}

\author{
Khadijah Q. ${ }^{1}$ and Heba M. ${ }^{1,2 \star}$ \\ ${ }^{1}$ Department of Textile Printing, Dyeing and Finishing, Faculty of Applied Arts, Helwan University, Egypt. \\ ${ }^{2}$ Department of Fashion Design, Faculty of Art and Design, King Abdul Aziz University, Saudi Arabia.
}

Accepted 8 February, 2013

\begin{abstract}
Dyeing is one of the most delightful textile arts which are an important branch in fashion design. Natural dye is a fascinating phenomenon that enticed researchers to their chemistry and production of fantastic novel hues to explore the point that no other dyes provide a better opportunity teaching how to protect and respect the environment. In this research, silk fabric was dyed by a mixture of different percentages of cochineal, curcumin and indigo powders in water-acetone co-solvent to possess an ecological acceptable for dye extraction. Extraction and dyeing processes were carried out together in one step at different $\mathrm{pH}$ values using sonic energy regarding the promising technique in saving energy. Silk dyeing exhibited a variety of shades according to the evaluated colorimetric data which could be attributed to their resonating structures, where the $\mathrm{pH}$ values play important parameter in this phenomenon and control the adsorption capacity of dyes onto silk. So, this research give the chance to produce different hues from the traditional natural dyes to improve the natural dyeing cultural heritage to meet the environmental future demands technology of high quality fantastic dyed patterns through an economical point of view.
\end{abstract}

Key words: Natural dyes, sonic energy, silk, eco-friendly dyeing.

\section{INTRODUCTION}

Coloring is one of the most delightful arts and the most important branches of manufacture; before the mid- $19^{\text {th }}$ century professional dyers of fine silks and woolens had to rely on such homely substances as dried insects, roots and leaves of plants, concluding that natural dyes are an education in ecology and ethics, where no other dyes provide a better opportunity teaching how to protect and respect the environment (Siva, 2007).

Nowadays, textile dyeing processing industry is one of the major environmental polluters; synthetic dyes have been in use globally in textile industries due to their availability, lower prices and wider ranges of bright shades with considerably improved color fastness properties in comparison with natural dyes (El-Nagar et al., 2005). According to the application of synthetic dyes, much water effluent generated during textile dyeing would pollute the environment as it contains a heavy load of chemicals, where it is estimated that 10 to $15 \%$ of the dye is lost in the effluent during the dyeing process (lqbal and Ashiq, 2007). Thus, renewed international interest has arisen in natural dyes which have gained momentum due to the increased awareness of the environmental and health hazards associated with synthetic dyes (Iabal and Ashiq, 2007). In addition to their creative potential, excellent fastness, softness, lustrous and bright where appearance is generally regarded as the most important textile attribute for consumer acceptance and endues (AlAmoudi and Osman, 2009). Natural dyes are classified

*Corresponding author. E-mail: hebalfm@yahoo.co.uk. 


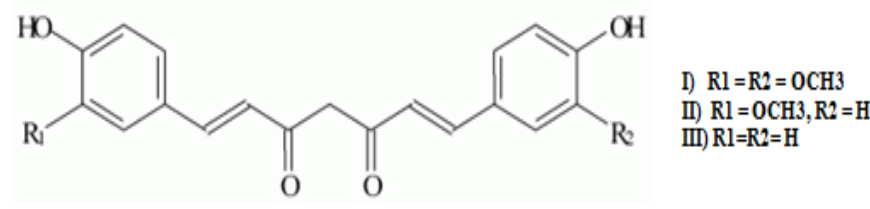

Figure 1. Chemical structure of Curcumin.

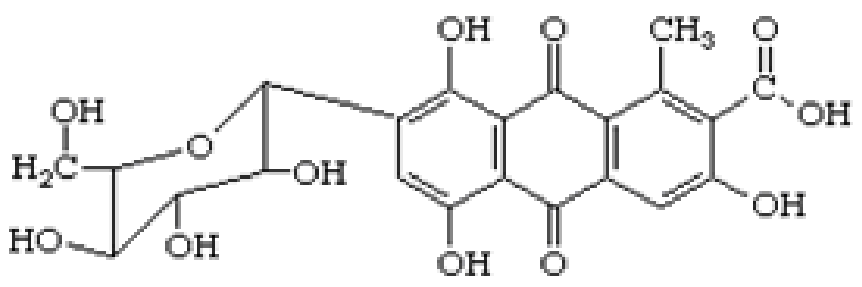

Figure 2. Chemical structure of carminic acid.

according to their chemical structure, sources method of application and color. The most traditional natural colors representing the principle colors are the yellow turmeric, the red cochineal, and the blue indigo.

Turmeric (Curcuma longa) is a naturally occurring yellow plant belonging to the ginger family; it has been known to the east Indians for several thousand years, its rhizome is used as a dietary spice coloring agent in foods and textiles. The main pigment compound in turmeric is called curcumin. As shown in Figure 1 (Ferreira et al., 2004), there are three curcuminoids, which make up 2 to $5 \%$ of the spice, and are all dicinnamoylmethane derivatives (Balasubramanian, 1990; Stankovic, 2004; Jayaprakasha et al., 2002, 2005): I:diferuloylmethane:1,7-Bis-(4-hydroxy-3-meth

oxyphenyl)-hepta-1,6-diene-3,5-dione $\mathrm{C}_{21} \mathrm{H}_{20} \mathrm{O}_{6}$ C.A.S. number: 458-37-7, Formula weight: 368), II:phydroxycinnamoylferuloylmethane:1-(4-Hydroxyphenyl)-

7-(4-hydroxy-3-methoxy phenyl)-hepta-1,6-diene-3,5dione, $\mathrm{C}_{20} \mathrm{H}_{18} \mathrm{O}_{5}$ : C.A.S. number: 33171-16-3, Formula weight: 338) and III: p,pdihidroxydicinnamoylmethane:1,7-Bis-(4-hydroxyphenyl)hepta-1,6-diene-3,5-dione.

Curcumin $I$ is the main coloring curcuminoids compound, it is an orange-yellow crystalline powder "natural yellow 3" practically insoluble in water and ether but soluble in ethanol, dimethylsulfoxide, and acetone. The principal coloring components of curcumin exhibit a keto-enol tautomerism and antioxidative properties (Jayaprakasha et al., 2002). It is s identified as [1, 6heptadiene-3,5-dione-1,7-bis(4-hydroxy-3-ethoxyphenyl)$(1 \mathrm{E}, 6 \mathrm{E})$ or diferuloylmethane $\left(\mathrm{C}_{21} \mathrm{H}_{20} \mathrm{O}_{6}\right)$; (Chemical formula: C19H16O4: C.A.S. number: 33171-05-0, Formula weight: 308 (Jiang et al., 2006; Aggarwal et al., 2003).

Most of natural red-color dyes have high solubility in water and act as acid dyes, which is why they bond to protein fibers (Siva, 2007; Kongkachuichaya et al., 2002). Cochineal is one of the species with great economic importance, since ancient times, is the 'American cochineal' Dactylopius coccus Costa (which some publications still refer to as Coccus cacti L.) because from the dried bodies of the adult females, where the little cochineal bug will give the most color when ground into a fine powder to obtain colors of dark burgundy to bright red to soft lilac and pink based on carmine. Carmine consists of an aluminum or calcium-aluminum lake on an aluminum hydroxide substrate of carminic acid; the coloring principle of cochineal (Marmion, 1991). Carminic acid is a hydroxyanthraquinone with a lateral chain of Cglycosyl and only one position free on the aromatic nucleus; in other words, it is an anthraquinino with other aglycones presents which are kermesic acid $(3,5,6,8$ tetrahydroxy-1-methyl-2-anthraquinone carboxylic acid), flavokermesic acid and laccaic acid D (3,6,8-trihydroxy-1methyl-2-anthraquinone carboxylic acid) (Allevi and Tyman, 1998). The composition of carminic acid as shown in Figure 2 was proposed to be $\mathrm{C}_{22} \mathrm{H}_{20} \mathrm{O}_{13}$, and it comprises approximately $10 \%$ of cochineal and 2 to $4 \%$ of its extract (Allevi and Tyman, 1998). It is used as brilliant red coloring agent (CAS Reg. No.: 1260-17-9; EINECS: 215-023-3; No. Shoultz: 1381; C.I.: light and heat stable of all the colorants and is 75470; Natural Red 4; E120). It is one of the more stable than many synthetic food colors (Siva, 2007).

Carminic acid has been widely used to color foods, beverages, textiles, pharmaceuticals and cosmetics products due its relatively high chemical and biological stability and its apparent lack of mutagenic, carcinogenic or genotoxic effects. This stability and the concomitant absence of toxicity have been attributed to the presence of the C-Glycosyl moiety. Besides, the color attributes, recently, also has been reported to be beneficial to health with potential antibiotic and antitumor properties. At the beginning of the $21^{\text {st }}$ century, it is predicted that many colors will be used for both their additional beneficial functions in the body, as well as, coloring effect (Allevi and Tyman, 1998).

Indigo which has been used for 4000 years is described as the blue of all old textiles. It seems to be the oldest known colorant; C.I. Vat Blue1 of Chemical Formula $\left(\mathrm{C}_{16} \mathrm{H}_{10} \mathrm{~N}_{2} \mathrm{O}_{2}\right)$ and Chemical Name: 2-(1,3dihydro-3-oxo-2H-indol-2-ylidene)-1,2-dihydro-3H-indol-3one. The Indigotin or Indican pigment is shown in Figure 3. It has been made from several different dye plants, such as Indigofera tinctoria and Indigo suffraticosa. Today, it retains its position as one of the world's most important industrial chemicals (Roessler and Jin, 2003). It is actually used for textile dyeing and printing where small amounts are used for dyeing wool and silk. In 2009, large spills of blue dyes had been reported for downstream of a blue jeans manufacturer in Lesotho. Because of its high value as a trading commodity and low oral toxicity, indigo 


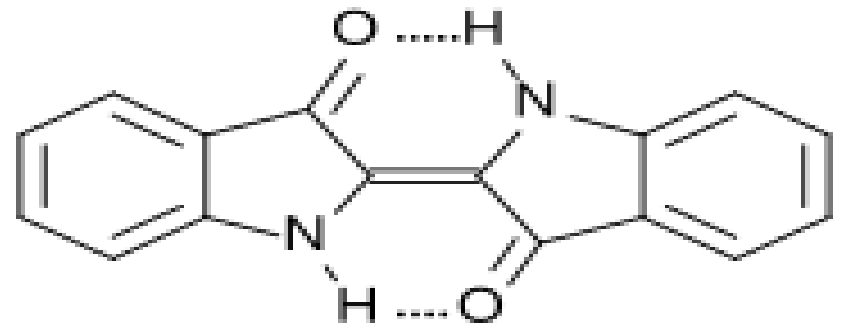

Figure 3. Chemical structure of Indigo.

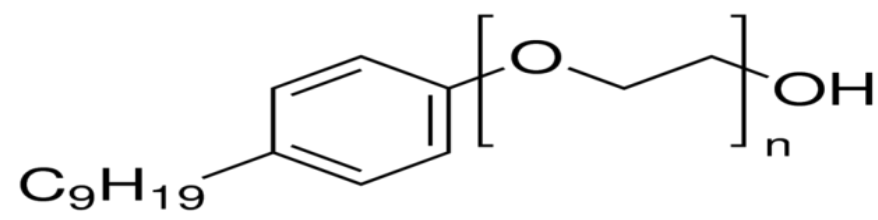

Figure 4. Chemical structure of Nonidet ${ }^{\circledR}$ P 40 Substitute.

was often referred to as Blue Gold. It is a so-called vat dye, which means that it needs to be reduced to its water soluble leuco-form before dyeing (Roessler and Crettenand, 2004). Natural dyes are generally prepared by boiling the crushed powder with water, and sometimes it is left to steep in cold water. Technology for production of natural dyes could vary from simple aqueous to complicated solvent systems to sophisticated supercritical fluid extraction techniques depending on the product and purity required (Siva, 2007). Several researches observed that extraction of natural dyes with co-solvents induced rise to extracts incompletely soluble in water (Heba and Gamal, 2011; Osman et al., 2009).

On the other hand, the use of ultrasonic in the extraction and dyeing methods to increase the yield of colorants is being attempted and represents a promising technique in saving energy, providing effectiveness in the silk treatment, dyeing, and mordanting in comparison with the conventional heating system (Heba and Heffernan, 2009; Heba and Gamal, 2011; Kamel et al., 2007; Vajnhandl and Le Marechal, 2005; Padma et al., 2006; Heba and Heffernan, 2010).

Previous scientific researchers were focused on the application of natural dyes on the different textile fabrics, mordants and mordanting methods, etc, recording their fastness properties and colorimetric data. In the present paper, there is an effort taking place to explore the availability of mixing turmeric, cochineal and indigo powders with different percentages to dye silk that was chosen because it is characterized as the queen of fibers having unique combination of properties as luster and appearance, and composed of different alpha amino acids orienting to form long chain polymer by condensation and polymerization that can be easily attached with natural dyes via ionic and hydrogen bonds to produce renewable aesthetic shades under the influence of $\mathrm{pH}$ values. This goal was assisted by water acetone co-solvent that possesses an ecological acceptable for dye extraction and sonic energy due to its considerable saving in processing time and chemical used; on the other hand, it is believed to exhibit only slight toxicity in normal use, and there is no strong evidence of chronic health effects if basic precautions are followed. It is relatively cheap and safe solvent, it has a much higher flashpoint than the alcoholic solvents methanol or ethanol, so is less likely to catch on fire lastly (www.madsci.org/.../1060116066.Ch.r.ht,

www.dow.com/productsafety/.../acetone). The renewable colors or shades of the dyed samples have been evaluated on computer color matching system in terms of $\mathrm{K} / \mathrm{S}$ and $\mathrm{L}^{*} \mathrm{a}^{*} \mathrm{~b}^{*}$ color coordinates. As a result, the study will complete the economical point of view together with the aesthetic duty and environmental image.

\section{EXPERIMENTAL}

\section{Materials}

Degummed and bleached plain Habotain silk fabric $\left(30 \mathrm{~g} / \mathrm{m}^{2}\right)$ purchased from Sherazad Com. NZ was further treated at a liquor ratio of $50: 1$ with $2 \mathrm{~g} / \mathrm{L}$ non-ionic surfactant; Nonidet $\AA$ P 40 Substitute purchased from Sigma-Aldrich NZ Ltd. It is 4Nonylphenyl-polyethylene glycol as shown in Figure 4. Scouring was carried out for $15 \mathrm{~min}$ at $80^{\circ} \mathrm{C}$, then thoroughly rinsed and dried at ambient temperature (Kongkachuichaya et al., 2002). Curcumin, indigo, and cochineal powders were purchased from Hands Ashford, Ltd Christchurch-New Zealand. Acetic acid, sodium hydroxide, sodium dithionite and acetone were of laboratory reagent grade.

\section{Extraction and dyeing processes}

$10 \% \mathrm{w} / \mathrm{v}$ curcumin and indigo powders were mixed together with percentages of 50:50 each of them, and percentage of 75:25 curcumin with indigo. $10 \% \mathrm{w} / \mathrm{v}$ curcumin and cochineal powders were mixed together with percentages of 50:50 each of them in addition to $75: 25$ curcumin with cochineal. On the other hand, 10\% $\mathrm{w} / \mathrm{v}$ cochineal and indigo powders were mixed together with percentages of 50:50 each of them in addition to 75:25 cochineal with indigo, and 25:75 cochineal with indigo.

Ultrasonic Elmasonic S30 apparatus (80W, $37 \mathrm{kHz}$ ) purchased from Elma Hans Schmidbauer $\mathrm{GmbH}$ and CO.KG) assisted both the extraction and dyeing processes of the mentioned mixtures percentages in one step, using $20 \%$ v.v of acetone: water cosolvent at $50^{\circ} \mathrm{C}$ for $1 \mathrm{~h}$ at different $\mathrm{pH}$ values of 3,7 , and 9 , using a material to liquor ratio of $1: 100$. "In case of indigo dyeing, $10 \mathrm{~g} / \mathrm{L}$ of sodium dithionite was added to the dye-bath". The dyed samples were washed with $2 \mathrm{~g} / \mathrm{L}$ of each of sodium carbonate, and Nonidet ${ }^{\circledR}$ P 40 Substitute at $60^{\circ} \mathrm{C}$ for 30 min using a material to liquor ratio of $1: 50$, then were thoroughly rinsed in warm and cold water, and left to dry at ambient temperature.

\section{Measurement}

Color strength of the dyed fabric samples, in terms of the $\mathrm{K} / \mathrm{S}$ 
values, was obtained by using the Kubelka Munk equation (Kubelka, 1948; Garland, 1993):

$F(R)=(1-R)^{2} / 2 R=K / S$

Where $K$ is the absorption coefficient and $S$ is the scattering coefficient for a colorant at a specific wavelength; $R$ is the fractional reflectance value of the dye on the substrate at the $\lambda_{\max }$. The $K / S$ value at $\lambda_{\max }$ is directly proportional to the concentration of dye on the substrate using Cary 100 UV-Vis Spectrophotometer. The CIE$\mathrm{Lab}$ values of the dyeing were measured on a CM-2600d Konica MINOLTA color meter, and the cylindrical co-ordinates of color were determined after exposure to irradiation from an Xe 150 watt arc lamp. The colors are given as CIE $L^{*} a^{*} b^{*}$ coordinates, as specified by the International Commission on Illumination with $L^{*}$ corresponding to brightness $(100=$ white, $0=$ black $)$, $a^{*}$ to the redgreen coordinate (positive sign $=$ red, negative sign $=$ green) and $b^{*}$ to the yellow-blue coordinate (positive sign = yellow, negative sign = blue) (Bechtold et al., 2003).

\section{RESULTS}

As shown in Figure 5, on mixing $50 \%$ of each of turmeric and indigo together, wavelengths of two colors were observed, representing the yellow color at $\lambda_{\max } 423,424$ and the bluish green color at $\lambda_{\max } 583-586$. For the yellow, the maximum color strength was achieved in the neutral medium, while for the bluish green; the maximum color strength value was achieved in the alkaline medium.

As shown in Figure 6, on mixing $75 \%$ turmeric with $25 \%$ indigo, wavelengths of two colors were observed, representing the yellow color at $\lambda_{\max } 416-453$, and the bluish green at $\lambda_{\max } 556$ - 588. For the yellow color, the maximum color strength was achieved in the neutral medium; on the other hand, the samples exhibited the yellow color in the three mediums, while for the bluish green color, and the maximum color strength value was achieved in both the acidic and neutral mediums.

As shown in Figures $5 \mathrm{C}$ and $6 \mathrm{C}$, the $\mathrm{pH}$ values of the dye bath have considerable effect on the color coordinate values. The lightness $L^{*}$ values increase in the acidic and alkaline mediums, and then these values were decreased when adjusting the $\mathrm{pH}$ of dye bath in the neutral medium. This observation relevant to lightness could be attributed with change in increase and decrease of color strength (\%) values with change in the $\mathrm{pH}$ of the dye bath. The tone of the samples at various $\mathrm{pH}$ of dye bath is less greener and more yellower in the acidic and neutral medium as indicated by the values of $a^{*}$ and $b^{*}$ These changes could be attributed with its resonating structures (Moeyes, 1993).

As shown in Figure 7, on mixing $50 \%$ of each of turmeric and cochineal together, wavelengths of two colors were observed, representing the yellow color at $\lambda_{\max } 419,426,446$ and the violet one at $\lambda_{\max } 556-569$, where the maximum color strength values of the two colors were achieved in the acidic medium'.

As shown in Figure 8, on mixing $75 \%$ curcumin with
$25 \%$ cochineal, wave lengths of two colors were observed, representing the yellow color at $\lambda_{\max }$ $419,423,444$ and the violet one at $\lambda_{\max } 568$, where the maximum color strength values of the two colors were achieved in the acidic medium.

As shown in Figures $7 \mathrm{C}$ and $8 \mathrm{C}$, the $\mathrm{L}^{*}$ (lightness or brightness) has its maximum value at $\mathrm{pH} 9$ in comparison with the other mediums in investigation which reflects the suitability of alkaline medium for obtaining bright color from the two dyes used. The $a^{*}$ and $b^{*}$ values have positive signs, reflecting the red color of cochineal and the yellow color of curcumin respectively, reaching their maximum content at $\mathrm{pH} 3$. Since cochineal dye is characterized by producing colors of dark burgundy to bright red to soft lilac and pink based on carmine ${ }^{14}$, it was recorded that silk samples dyed with mixtures of i) $50 \%$ of each of curcumin and cochineal, ii) 75 curcumin with 25 cochineal exhibited a greenish yellow color in the acidic medium, yellow color in the alkaline medium and yellowish orange color in the neutral medium with much yellower color in case of $75 \%$ curcumin with $25 \%$ cochineal.

As shown in Figure 9, on mixing $75 \%$ cochineal with $25 \%$ indigo, wavelengths of two colors were observed, representing red color in the acidic medium, to violet color in the neutral and alkaline mediums at $\lambda_{\max } 521$, 558,581 , respectively. The maximum color strength value was achieved in the alkaline medium. The $L^{*}$ (lightness or brightness) has its maximum value at $\mathrm{pH} 7$ in comparison with the other mediums in investigation which reflects the suitability of neutral medium for obtaining bright color from the two dyes. The $\mathrm{a}^{*}$ values have positive signs, reflecting the red color of cochineal which achieve its maximum content at $\mathrm{pH} 3$. The $\mathrm{b}^{*}$ values have negative signs reflecting the blue color of indigo which achieve its maximum value at $\mathrm{pH} 9$.

As shown in Figure 10, on mixing $50 \%$ cochineal with $50 \%$ indigo, a violet color was observed at $\lambda_{\max }(568,589$, and 581) $\mathrm{nm}$ in the acidic, neutral, and alkaline mediums, respectively. The maximum color strength value was achieved in the acidic medium. The $L^{*}$ (lightness or brightness) has its maximum value at $\mathrm{pH} 7$ in comparison with the other mediums in investigation which reflects the suitability of neutral medium for obtaining bright color from the two dyes. The $a^{*}$ values have positive signs, reflecting the red color of cochineal which achieve its maximum content at $\mathrm{pH} 3$. The $\mathrm{b}^{*}$ values have negative signs reflecting the blue color of indigo which achieve its maximum value at $\mathrm{pH} 9$.

As shown in Figure 11, on mixing $25 \%$ cochineal with $75 \%$ indigo, a violet color was observed at $\lambda_{\max } 574 \mathrm{~nm}$ in the neutral medium and $571 \mathrm{~nm}$ in the alkaline and acidic mediums. The maximum color strength value was achieved in the neutral medium. The $L^{*}$ (lightness or brightness) has its maximum value at $\mathrm{pH} 3$ in comparison with the other mediums in investigation which reflects the suitability of acidic medium for obtaining bright color from 

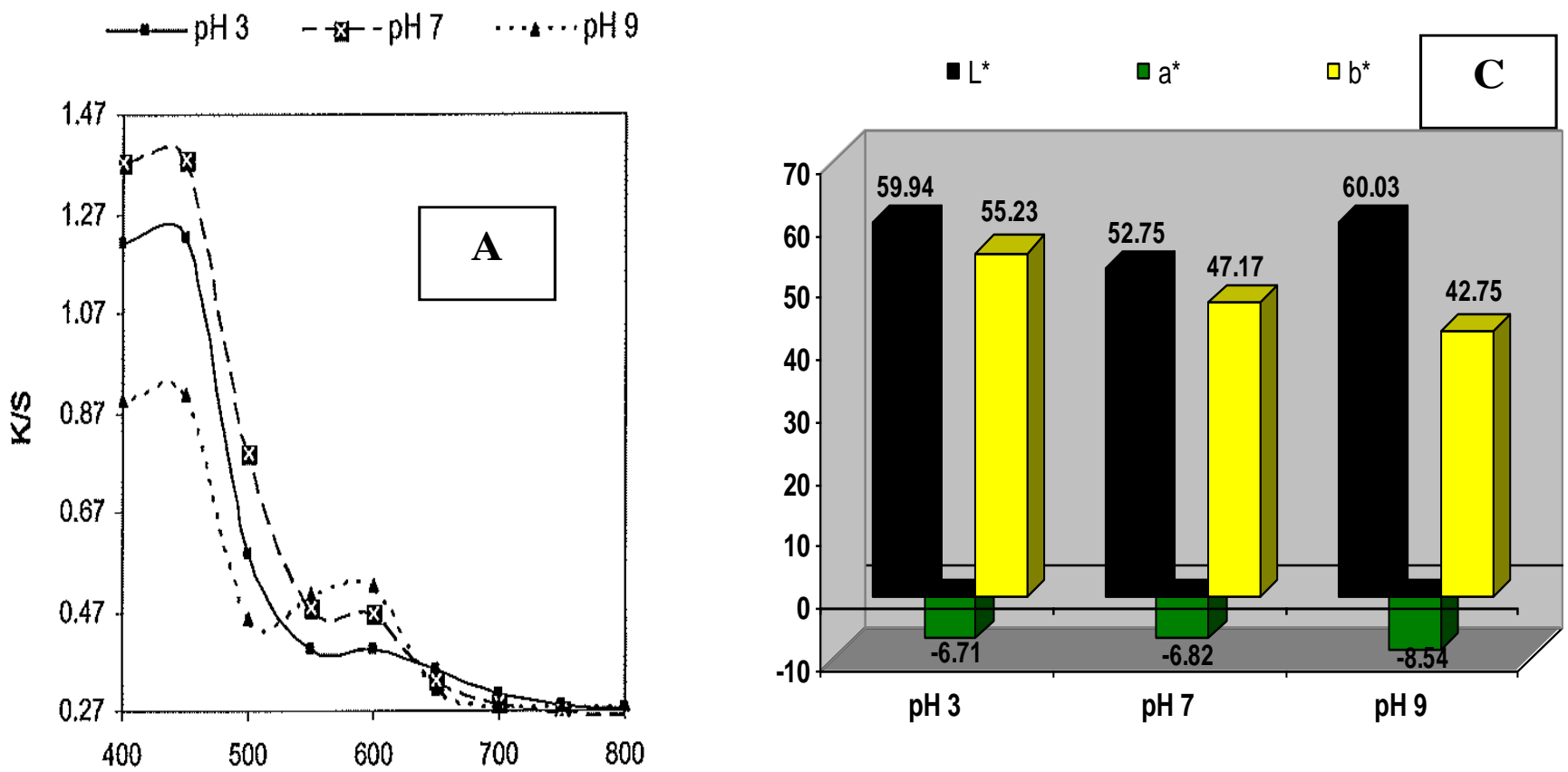

Wave length

$\rightarrow-\mathrm{pH} 3-\mathrm{x}-\mathrm{pH} 7 \cdots+\cdots \mathrm{pH}$
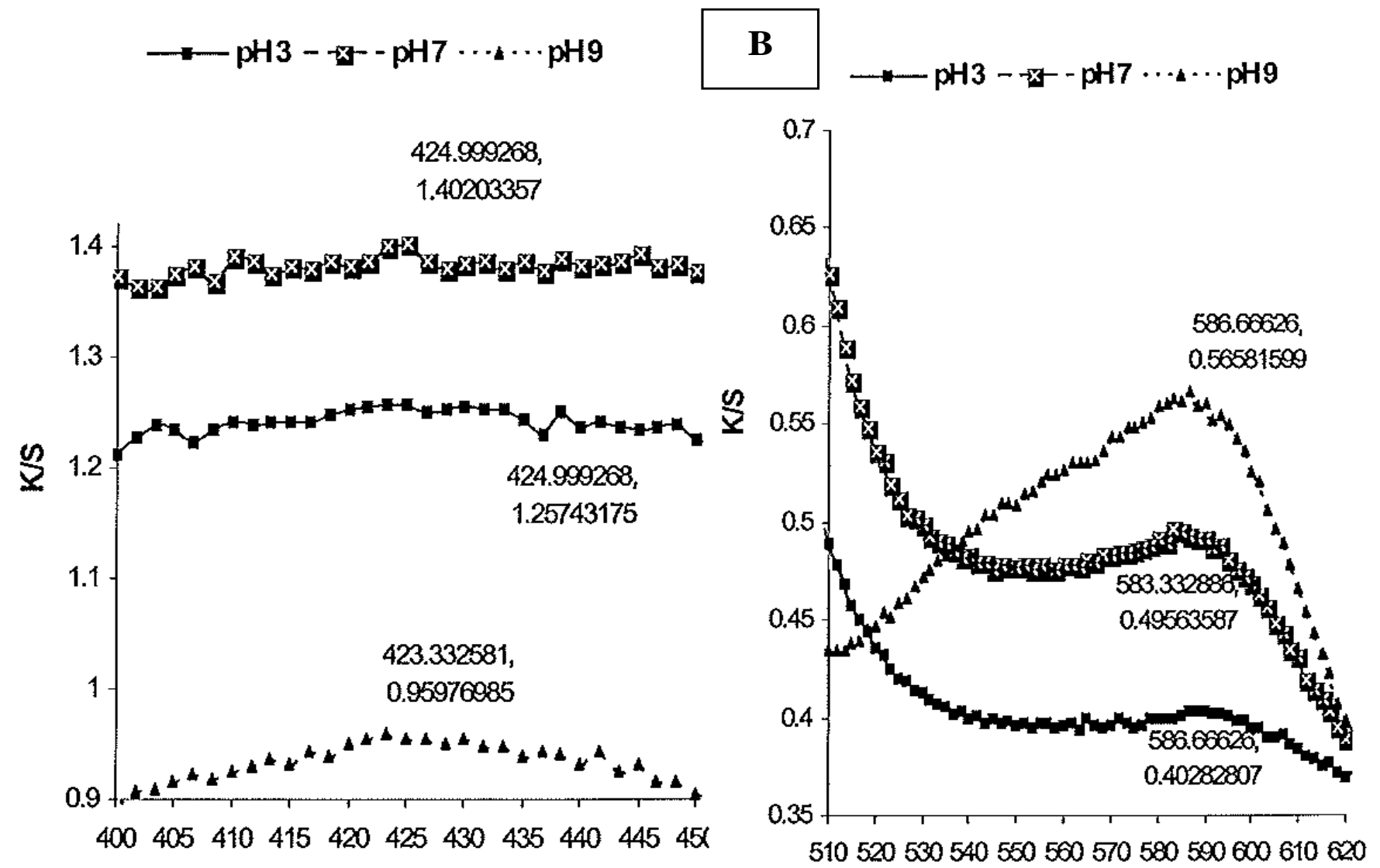

\section{Wave length}

Wave length

Figure 5. $\mathrm{A}=$ Effect of $\mathrm{pH}$ values on wave length and $\mathrm{K} / \mathrm{S}$ of silk dyed with an extract composed of a mixture of $50 \%$ turmeric with $50 \%$ indigo $\mathrm{B}=$ Identification of the highest wave lengths and $\mathrm{K} / \mathrm{S}$ values according to figure $4 \mathrm{~A}$. $\mathrm{C}=\mathrm{Effect}$ of $\mathrm{pH}$ values on the $\mathrm{CIE}$ Lab values of silk dyed with $50 \%$ curcumin and $50 \%$ indigo extract at different $\mathrm{pH}$ values. 

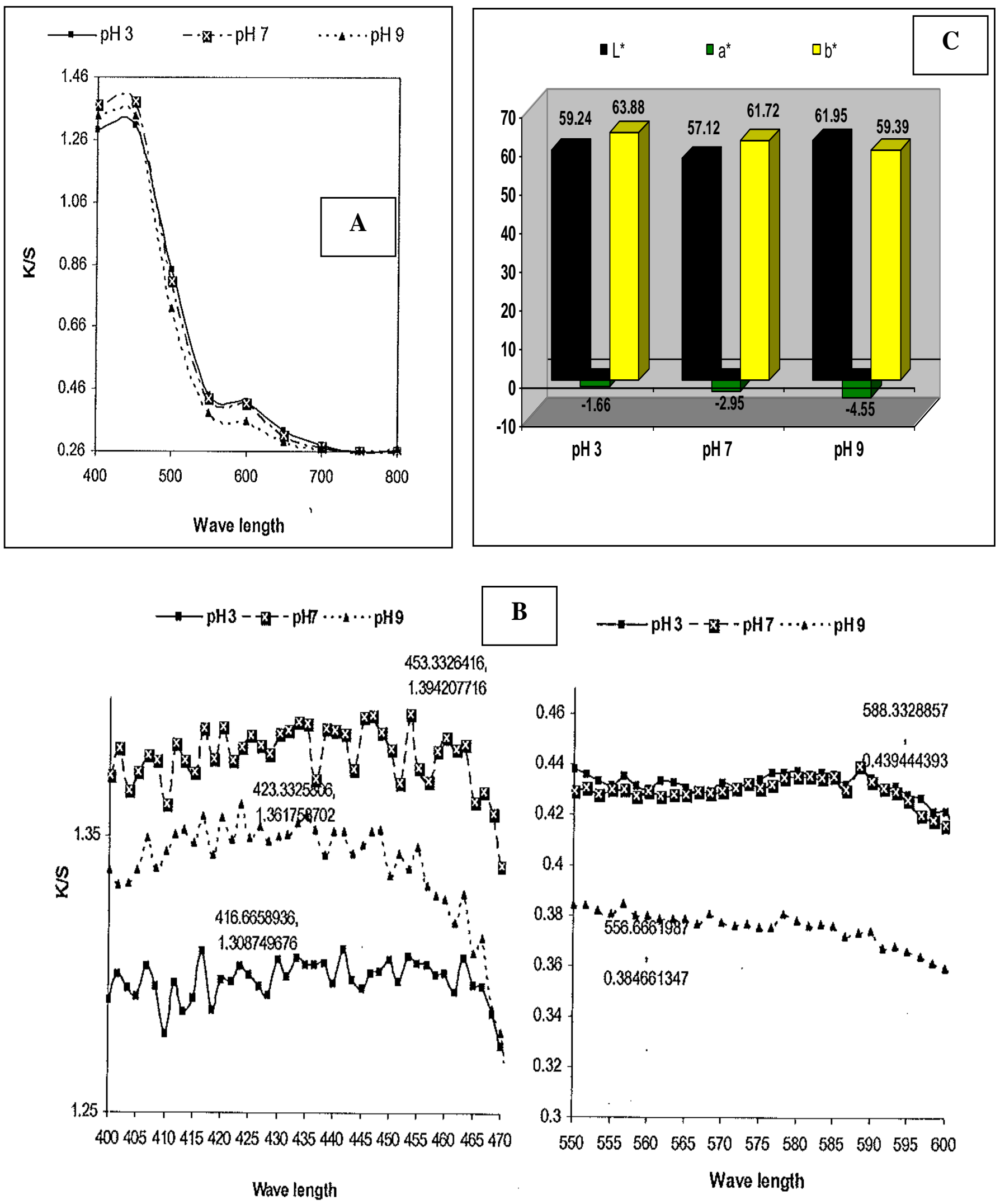

Figure 6. $\mathrm{A}=$ Effect of $\mathrm{pH}$ values on wave length and $\mathrm{K} / \mathrm{S}$ of silk dyed with an extract composed of a mixture of $75 \%$ turmeric with $25 \%$ indigo $\mathrm{B}=$ Identification of the highest wave lengths and $\mathrm{K} / \mathrm{S}$ values according to Figure $5 \mathrm{~A} . \mathrm{C}=\mathrm{Effect}$ of $\mathrm{pH}$ values on the $\mathrm{CIE}-\mathrm{Lab}$ values of silk dyed with $75 \%$ curcumin and $25 \%$ indigo extract at different $\mathrm{pH}$. 

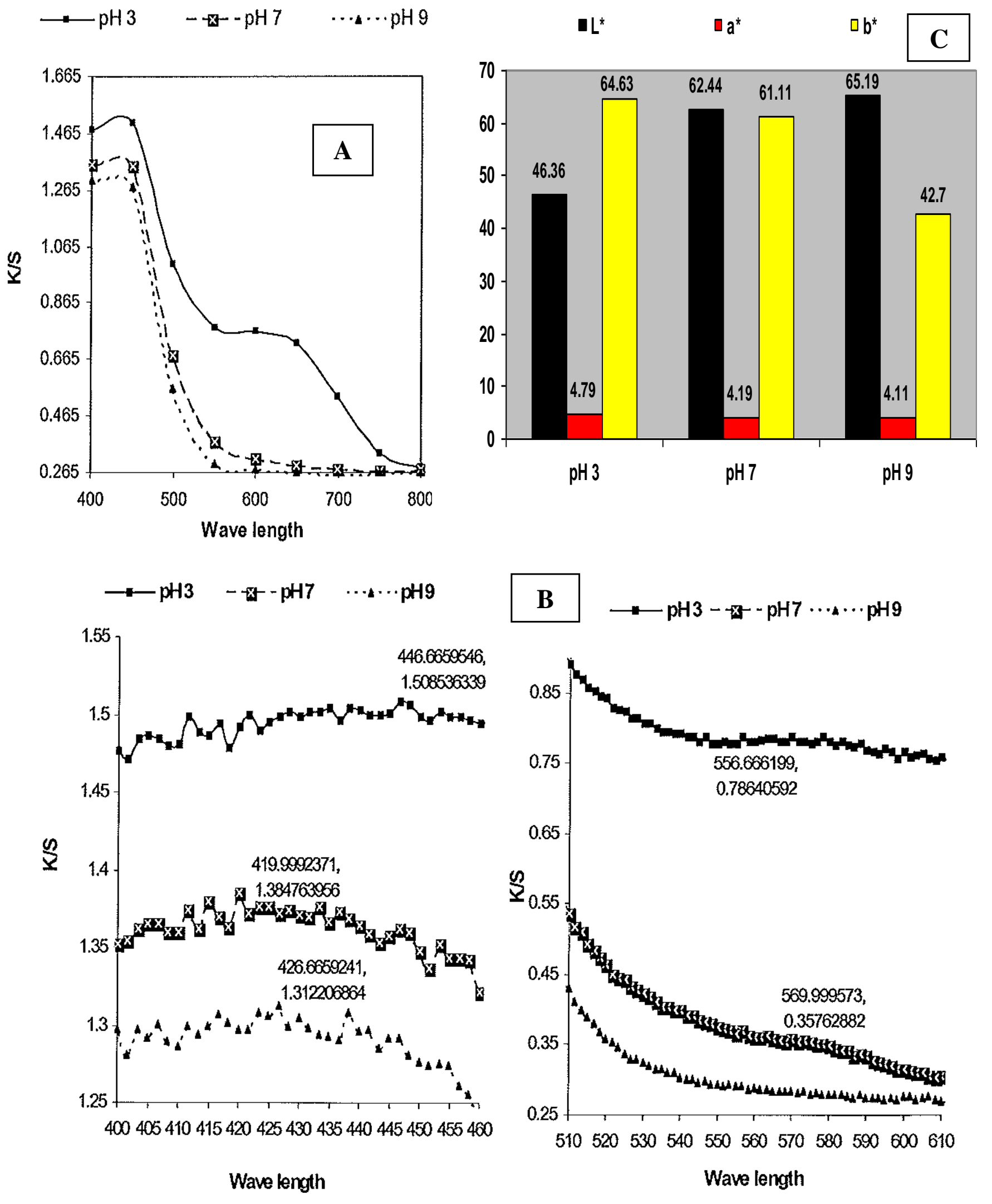

Figure 7. $\mathrm{A}=$ Effect of $\mathrm{pH}$ values on wave length and $\mathrm{K} / \mathrm{S}$ of silk dyed with an extract composed of a mixture of $50 \%$ curcumin with $50 \%$ cochineal $\mathrm{B}=$ Identification of the highest wave lengths and $\mathrm{K} / \mathrm{S}$ values according to Figure $6 \mathrm{~A}$. $\mathrm{C}=\mathrm{Effect}$ of $\mathrm{pH}$ values on the CIE-Lab values of silk dyed with $50 \%$ curcumin and $50 \%$ cochineal extract at different $\mathrm{pH}$ values. 

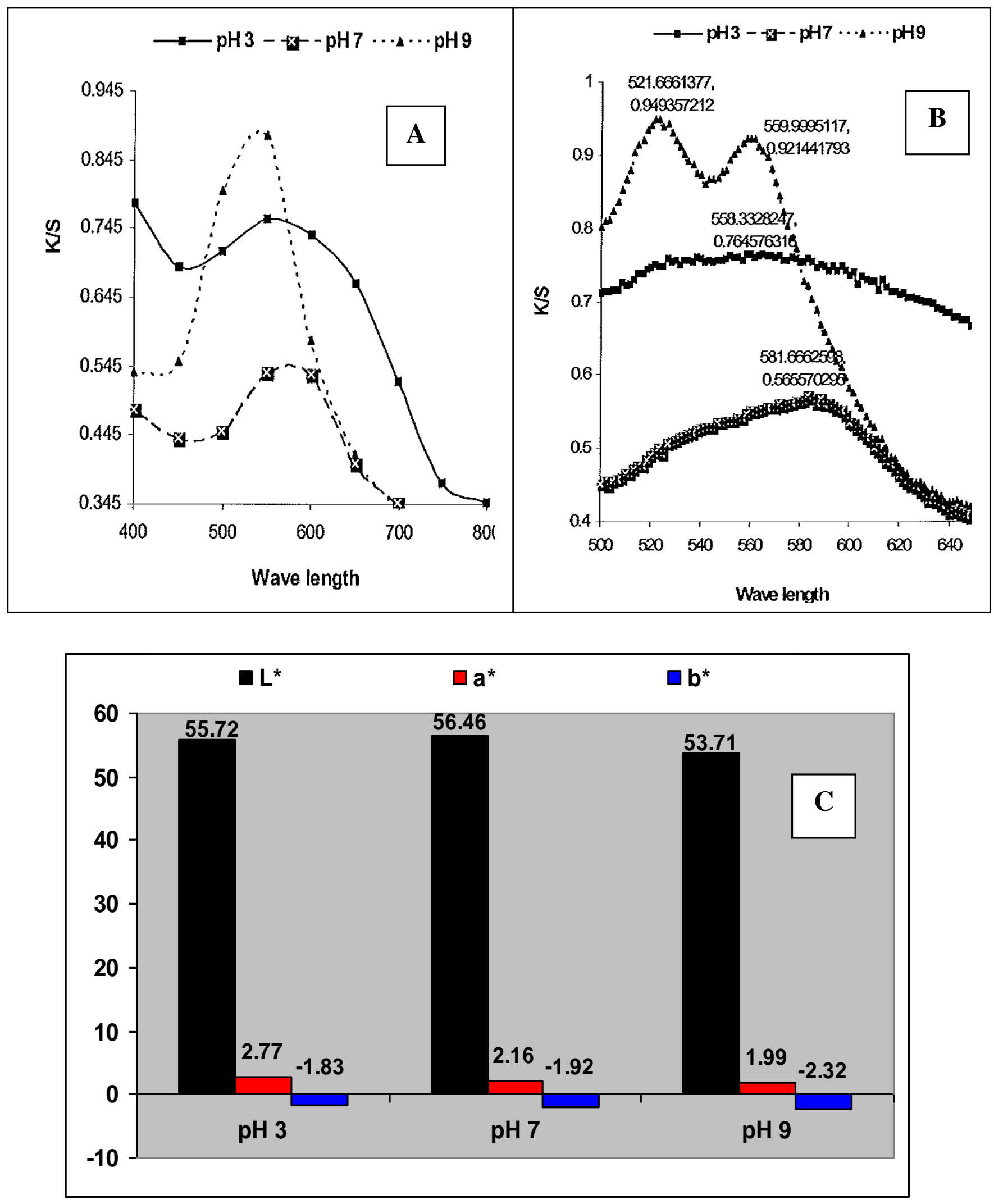

Figure 9. $\mathrm{A}=$ Effect of $\mathrm{pH}$ values on wave length and $\mathrm{K} / \mathrm{S}$ of silk dyed with an extract composed of a mixture of $75 \%$ cochineal with $25 \%$ indigo $\mathrm{B}=$ Identification of the highest wave lengths and $\mathrm{K} / \mathrm{S}$ values according to Figure $8 \mathrm{~A} . \mathrm{C}=\mathrm{Effect}$ of $\mathrm{pH}$ values on the $\mathrm{CIE}$ Lab values of silk dyed with $50 \%$ cochineal and $50 \%$ indigo extract at different $\mathrm{pH}$ values. 

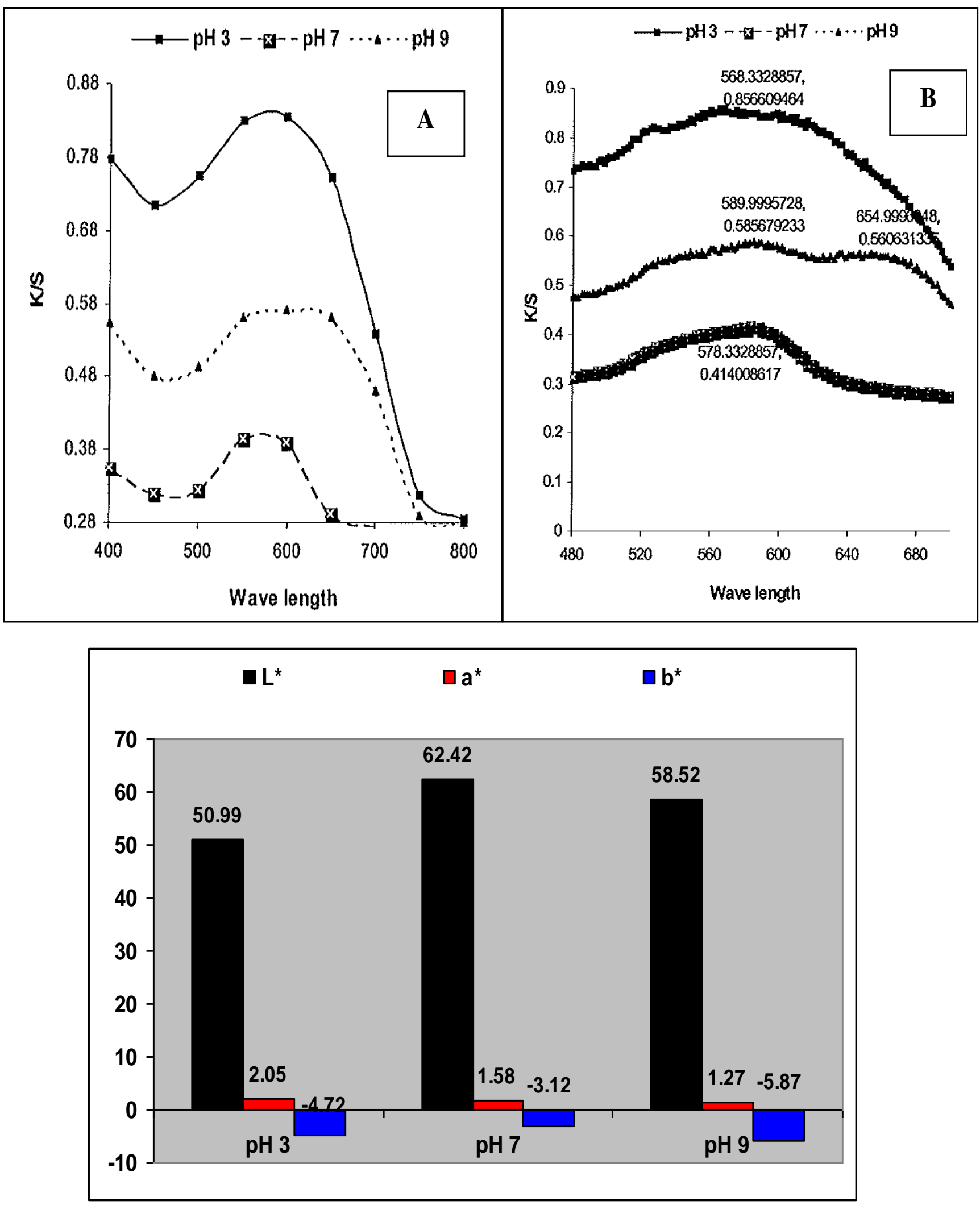

Figure 10. $\mathrm{A}=$ Effect of $\mathrm{pH}$ values on wave length and $\mathrm{K} / \mathrm{S}$ of silk dyed with an extract composed of a mixture of $50 \%$ cochineal with $50 \%$ indigo $\mathrm{B}=$ Identification of the highest wave lengths and $\mathrm{K} / \mathrm{S}$ values according to figure $9 \mathrm{~A} . \mathrm{C}=\mathrm{Effect}$ of $\mathrm{pH}$ values on the CIE-Lab values of silk dyed with $25 \%$ cochineal and $75 \%$ indigo extract at different $\mathrm{pH}$ values. 

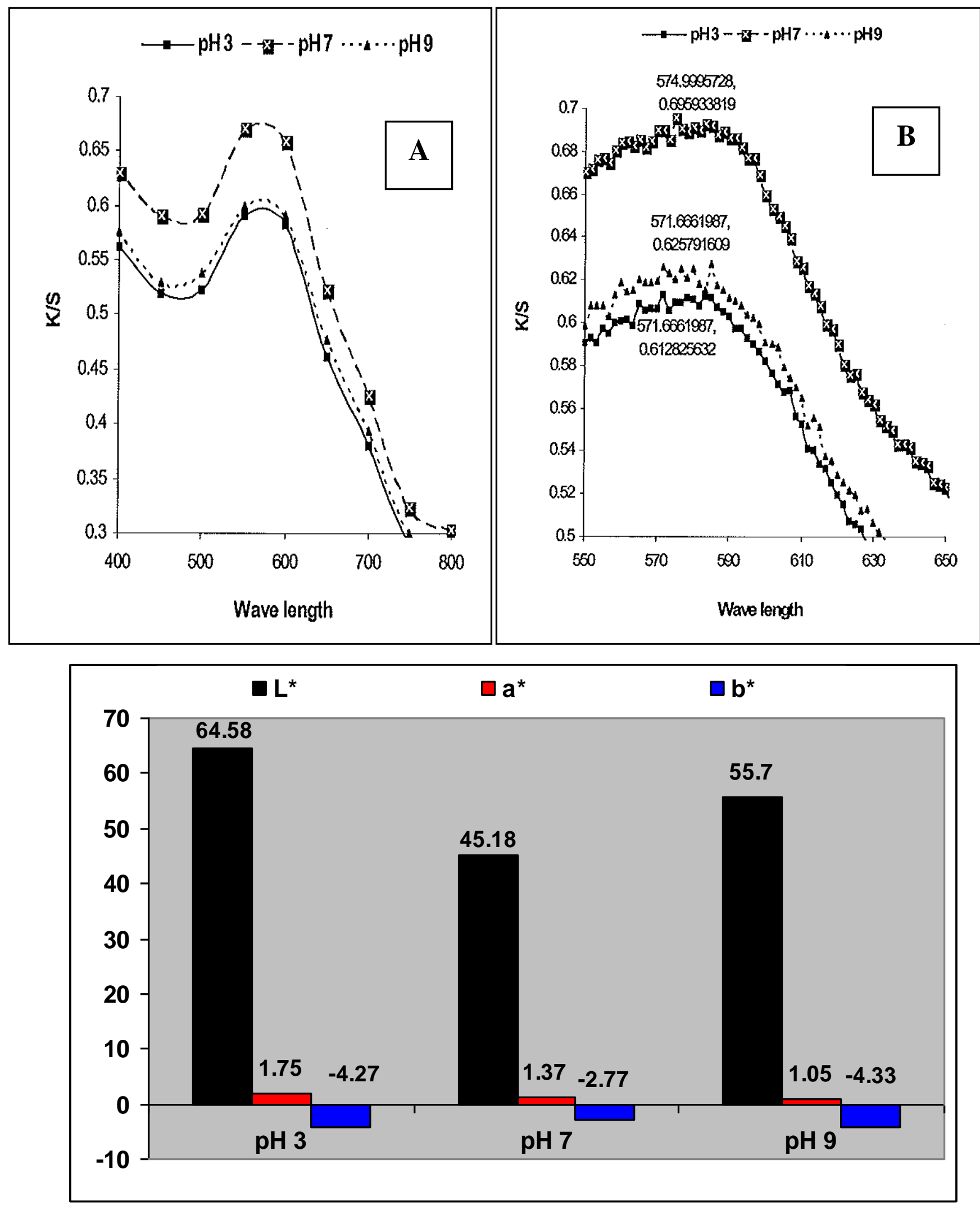

Figure 11. $\mathrm{A}=$ Effect of $\mathrm{pH}$ values on wave length and $\mathrm{K} / \mathrm{S}$ of silk dyed with an extract composed of a mixture of $25 \%$ cochineal with $75 \%$ indigo $B=$ Identification of the highest wave lengths and $\mathrm{K} / \mathrm{S}$ values according to Figure $10 \mathrm{~A} . \mathrm{C}=\mathrm{Effect}$ of $\mathrm{pH}$ values on the $\mathrm{CIE}$ Lab values of silk dyed with $75 \%$ cochineal and $25 \%$ indigo extract at different $\mathrm{pH}$ values $\mathrm{h}$. 
the applied two dyes. The $\mathrm{a}^{*}$ values have positive signs, reflecting the red color of cochineal which achieve its maximum content at $\mathrm{pH} 3$. The $\mathrm{b}^{*}$ values have negative signs reflecting the blue color of indigo which achieve its maximum value at $\mathrm{pH} 9$.

\section{DISCUSSION}

The $\mathrm{pH}$ of the dye solution is one of the most important parameters controlling the adsorption capacity of dye onto silk (Wang et al., 1997; Christie et al., 2000). The effect of $\mathrm{pH}$ on the spectroscopy studies of the mixtures of turmeric and indigo onto silk were evaluated in Figures 4 and 5. Results indicated that the maximum color strength values were clearly achieved at acidic medium. From the Greek chromophorus (chromos color), a chromophore is generally a groups of atoms in a molecule responsible for the interaction with the radiation at certain wavelength; example of common chromophore is conjugated multiple bond, rich in electrons, where the energy of the light which passes through the sample is absorbed by some electrons and they are in that way "excited" to a higher energetic level (state). UV/Visible spectrums of pure curcumin in distilled water showed two well defined $\lambda_{\max }$ at 259 and $405 \mathrm{~nm}$, but it absorbs maximally at 415 to $420 \mathrm{~nm}$ in acetone (Stankovic, 2004). The similar $\lambda_{\max }$ were obtained in the spectra of curcumin obtained through extraction from turmeric rhizomes and through dyed fabric in acetone / water solution as well. The presence of the two $\mathrm{C}=\mathrm{O}$ groups seems to suggest that the $405 \mathrm{~nm}$ in the visible region is due to the $n-\pi$ * transition of conjugated chromophore. The $\lambda_{\max }$ at 259 is due to the $\pi-\pi^{*}$ transition that is attributed to alternate double bonds present in the curcumin.

Curcumin is an oil-soluble pigment, practically insoluble in water at acidic and neutral $\mathrm{pH}$, and soluble in alkali. In solutions, the principal coloring components of curcumin exhibit keto-enol tautomerism and, depending on the solvent, up to $95 \%$ are in the enol form (Stankovic, 2004). It has a brilliant yellow hue at $\mathrm{pH} 2.5$ to 7 and takes on a red hue at $\mathrm{pH}>7$, and its decomposition was $\mathrm{pH}$ dependent and occurred faster at neutral to basic conditions (Balasubramanian, 1990). At $\mathrm{pH}<1$, aqueous solutions of diferuloylmethane have a red color which indicates the protonated form $(\mathrm{H} 4 \mathrm{~A}+)$. In the $\mathrm{pH}$ range 1 to 7 , the majority of diferuloylmethane species are in the neutral form (H3A). Water solubility is very low in $\mathrm{pH}$ range 1 to 7 and solutions are yellow. At $\mathrm{pH}>7.5$, the color changes to red. The UV visible spectral data of curcumin reveals two peaks, one in the visible region $\lambda_{\max }=(420 \mathrm{~nm}, \log E=4.77)$ and the other, $\lambda_{\max }=(265$ $\mathrm{nm}$ with $\log E=4.18)$. The absorption peak in the visible region $\left(\lambda_{\max }=420 \mathrm{~nm}\right)$ explains the yellow color of the dye. On the other hand, the UV visible spectral data of indigo reveals $580 \mathrm{~nm}$ (Stankovic, 2004).

Resonating structure of some natural dyes might be determined via studying curcumin case; Curcumin is an oil-soluble pigment, practically insoluble in water at acidic and neutral $\mathrm{pH}$, and soluble in alkali. In solutions, the principal coloring components of curcumin exhibit ketoenol tautomerism and, depending on the solvent, up to $95 \%$ are in the enol form. It has a brilliant yellow hue at $\mathrm{pH} 2.5$ to 7 and takes on a red hue at $\mathrm{pH}>7$, and its decomposition was $\mathrm{pH}$ dependent and occurred faster at neutral to basic conditions (Moeyes, 1993).

At $\mathrm{pH}<1$, aqueous solutions of diferuloylmethane have a red color which indicates the protonated form $(\mathrm{H} 4 \mathrm{~A}+)$. In the $\mathrm{pH}$ range 1 to 7 , the majority of diferuloylmethane species are in the neutral form (H3A). Water solubility is very low in $\mathrm{pH}$ range 1 to 7 and solutions are yellow. At $\mathrm{pH}>7.5$ the color changes to red. The pKa values for the dissociation of the three acidic protons in Compound 1 (forms H2A-, HA2- and A3-) have been determined to be $7.8,8.5$ and 9.0, respectively as shown in Figure 12 (Stankovic, 2004).

The UV visible spectral data of curcumin reveals two peaks, one in the visible region $\lambda_{\max }=(420 \mathrm{~nm}, \log E=$ 4.77) and the other, $\lambda_{\max }=(265 \mathrm{~nm}$ with $\log E=4.18)$. The absorption peak in the visible region $\left(\lambda_{\max }=420 \mathrm{~nm}\right)$ explains the yellow color of the dye. On the other hand, the UV visible spectral data of indigo reveals $580 \mathrm{~nm}$.

A possible mechanism for color change upon addition of $\mathrm{OH}$ - to curcumin is shown in Figure 13. The simplest explanation is that phenolic $\mathrm{OH}$ is acidic due to the operation of resonance and readily reacts with $\mathrm{OH}^{-}$. These results in the anion or dianions were represented in Figure 13, the structures with more detailed and quantitative theoretical analysis would, of course, have to be based on quantum mechanical calculations. The presences of certain groups called chromophores are often responsible for color. Curcumin has two $\mathrm{C}=0$ groups separated by $\mathrm{CH}_{2}$. The $\mathrm{C}=0$ groups are adjacent to alternant array of double bonds. The presence of the two $\mathrm{C}=0$ groups seems to suggest that the $420 \mathrm{~nm}$ peak in the visible region is due to the $n \ldots . . \pi^{*}$ transition of the $\mathrm{CO}$ chromophore. Thus, the visible transition of curcumin could be attributed to the $n . . . \pi^{*}$ transition. The other band with $\lambda_{\max } \mathrm{nm}(\log E=4.18)$ should then be due to a $\pi \ldots \pi^{*}$ transition attributed to the altemant set of double bonds present in the neutral curcumin. It was reasonably successful in predicting the $\lambda_{\max }$ of curcumin; it was extended to explain the red shift observed upon addition of $\mathrm{OH}$-. Since the addition of $\mathrm{OH}$ - to curcumin results in the anion II, III, or IV the $L$ value in expression (I) must be increased due to the delocalization of the negative charge from one end of the model compound to the other end. Alternatively, the predominantly $\odot \mathrm{C}-0$ bond in phenolic $\mathrm{C}-\mathrm{OH}$ now attains $\pi$ character in the anion. Since the $C-O$ - bond length is derived from phenolic $C$ $\mathrm{OH}$, it should be between aromatic $\mathrm{C}=\mathrm{O}$ and phenolic $\mathrm{C}$ 0 . It is well known that spectral shift in the $n \ldots . . \pi^{*}$ transition due to extension of conjugation is approximately half of the value of $\Delta \lambda_{\max }\left(\pi \ldots . . \pi^{*}\right)$. This 
<smiles>CCCCOc1cc(/C=C/C(=O)CC(=O)/C=C/c2ccc(O)c(OC)c2)ccc1O</smiles><smiles>CCCCCOc1cc(/C=C/C(=O)CC(=O)/C=C/c2ccc(O)c(OC)c2)ccc1O</smiles><smiles>CCCCCOc1cc(/C=C/C(=O)CC(=O)/C=C/c2ccc(O)c(OC)c2)ccc1O</smiles><smiles>CCCCCCCCCCCCCCC(=O)CC(=O)C=Cc1ccc(OC)c(OC)c1</smiles>

$A^{3-}$<smiles>CCCCOc1cc(/C=C/C(=O)CC(=O)/C=C/c2ccc(OC)c(OC)c2)ccc1OC</smiles>

Figure 12. The pKa values for the dissociation of the three acidic protons.

gives $\lambda_{\max }$ for the anion between 479 and $500 \mathrm{~nm}$ depending on which parameter is used for the neutral curcumin $\lambda_{\text {max. }}$. In any case, this falls in the greenish blue to bluish green region of the spectrum, and hence the complement orange-red color is expected for the anionic curcumin. Experimentally, a red color is observed upon addition of $\mathrm{OH}$ - to curcumin. The addition of $\mathrm{OH}$ - group was modeled by a resonating anionic compound as shown in the top half of Structure II in Figure 5, this was the fact that the $\pi^{*}$ orbital that is occupied in the anion could be taken into account. This resulted in the lowering of the $\pi^{*}$ orbital in addition to extension of conjugation. The first $\pi \ldots \pi^{*}$ transition for the anion corresponded to the transition between the sixth highest occupied orbital and the lowest unoccupied (seventh orbital) for the anion while the corresponding transition for the neutral curcumin $\left(\pi \ldots \pi^{*}\right)$ corresponded to a transition between the highest occupied $\pi$ (fifth) orbital to the lowest unoccupied $\pi^{*}$ (sixth) orbital. The approximate shift, that

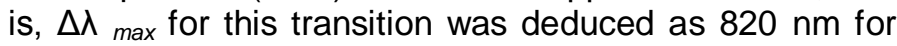
the UV band and $550 \mathrm{~nm}$ for visible band. This changes the $\Delta \lambda_{\max }$ of the $\mathrm{n} \ldots \pi^{*}$ transition of the anionic curcumin in the alkaline medium to approximately $490 \mathrm{~nm}$. This will evidently give a red color to curcumin in alkaline medium.
A sound qualitative explanation of the red shift in the visible band of curcumin is that the $\pi^{*}$ is stabilized both by extension of conjugation and its occupancy for Structures II-IV. As a result the transition gap for the $\mathrm{n}$ $\ldots . . \pi *$ transition reduces, although the lowest unoccupied $\pi^{*}$ orbital is different for the neutral curcumin as opposed to the anionic curcumin leading to a red shift. Note that the $n . \ldots \pi^{*}$ transition of neutral curcumin is much stronger ( $\log \varepsilon=4.77$ ). The main reason for the much larger extinction coefficient for curcumin is primarily due to the $\pi$-donating alternant system $>f$ conjugated sets of double bonds which can extend the $\pi$-bonding through resonance (Stankovic, 2004).

As stated before, since cochineal dye is characterized by producing colors of dark burgundy to bright red to soft lilac and pink based on carmine (Allevi and Tyman, 1998), it was recorded that the silk samples dyed with mixtures of i) $75 \%$ cochineal with $25 \%$ indigo exhibited violet color in the three mediums, ii) $50 \%$ of each of cochineal and indigo exhibited violet color in the alkaline and neutral medium, while grayish blue in the acidic medium and iii) $25 \%$ cochineal with $75 \%$ indigo exhibited violet color in the neutral medium while grayish blue in the acidic and alkaline mediums. From the mentioned 


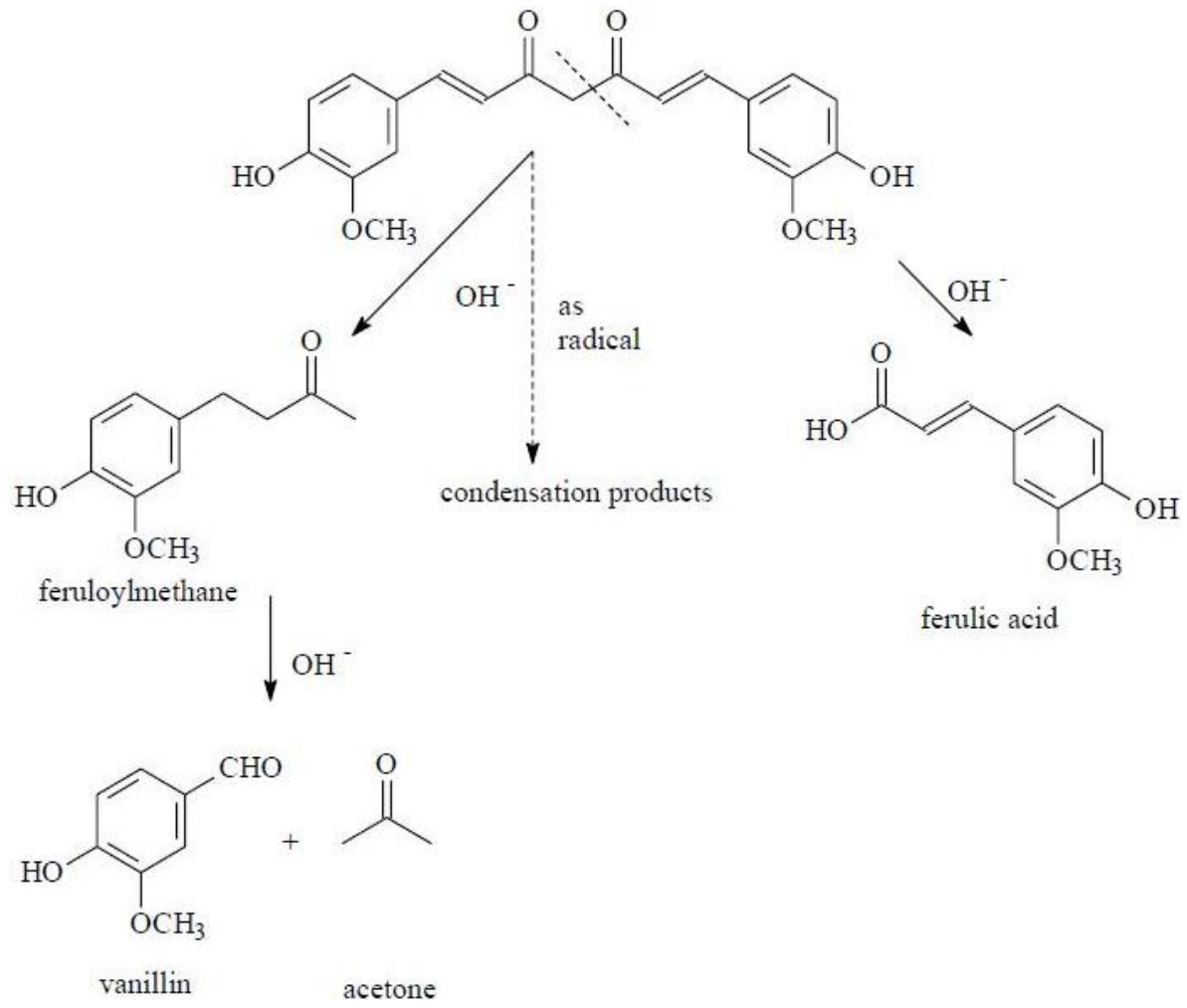

Figure 13. Mechanism for color change upon addition of $\left(\mathrm{OH}^{-}\right.$to curcumin).

results, mixtures of dyes exhibited different colors or shades according to $a^{*}$ and $b^{*}$ values which could be attributed with their resonating structures (Montazer and Parvinzadeh, 2004)

Indigo is a vat dye, soluble in alkaline medium but in acidic medium its solubility will be in the least amount. Curcumin acts as direct dye, while cochineal acts as acidic one. The acidic medium is suitable for curcumin and cochineal, but not suitable for indigo. Therefore, the yellow and red color of curcumin and cochineal reached their maximum values in the acidic medium. While the blue color of indigo reached its highest values in the alkaline medium.

The $\mathrm{pH}$ of the dye solution is one of the most important parameters controlling the adsorption capacity of dyes onto silk (Moeyes, 1993; Christie et al., 2000). For curcumin and cochineal dyes, the possible mechanisms for the effect of $\mathrm{pH}$ on adsorption of dyes are likely to be ionic interactions of the dye anions with the protonated amino groups on the silk fiber. The effect of dye bath $\mathrm{pH}$ can be attributed to the correlation between dye structure and silk fibers. Since the dye used is a water-soluble dye containing carboxyl groups, it would interact ionically with the protonated terminal amino groups of silk fibers at acidic $\mathrm{pH}$ via ion exchange reaction. The anion of the dye has a complex character, and when it is bound on fiber, further kinds of interactions take place together with ionic forces. This ionic attraction would increase the dyeability of the fiber. At $\mathrm{pH}>3$, however, the ionic interaction between the carboxylate anion of the dye and silk fibers decreases due to the decreasing number of protonated terminal amino groups of silk and thus lowering its dyeability.

It is worth noting that the lower dyeability at $\mathrm{pH}>3$ may be attributed to the enhanced desorption of the dye as its ionic bond is getting decreased (Cardon, 2007). In case of indigo dye, different forms of indigo existed in solution, each one having a different substantivity for the fiber. The non-ionic form had the highest, whilst the ionic ones had relatively less substantivity. Silk fibers could best be dyed in the acidic to slightly alkaline $\mathrm{pH}$ range. The chemistry of the dye-bath and fiber were considered, in order to explain the effect of $\mathrm{pH}$ on color strength. Hydrogen bonding and ionic interactions seemed to be the main reason for the exhaustion of dye onto silk fiber, where hydrogen bonding occurred between the hydroxyl groups and amide groups, while ionic interactions worked at low $\mathrm{pH}$ values between the ionized and end-amino groups of the dye and fiber respectively (Christie et al., 2000). On the other hand, ultrasonic represented a promising technique in saving energy by providing additional energy, which was generally attributed to the cavitation phenomenon in a liquid medium, in addition to other mechanical effects, that is, dispersion, degassing, diffusion, and the Intense agitation of the liquid. This phenomenon led to lowering the temperature and 
reducing the time needed for the extraction, and the dyeing processes (Heba and Heffernan, 2009; Heba and Gamal, 2011; Kamel et al., 2007; Vajnhandl and Le Marechal, 2005; Padma et al., 2006; Heba and Heffernan, 2010) By the way of extraction with acetone, water co-solvent includes the dipole moment, dielectric constant and refractive index values. The solvent polarity can change the position of the absorption or emission band of molecules by solvating a solute molecule or any other molecular species introduced into the solvent matrix (Muhammed et al., 2008; Heba and Gamal, 2011).

\section{Conclusion}

Color is one of the most fascinating phenomena which were enticed to chemistry as is well known, full comprehension compound needs knowledge of quantum chemistry and spectroscopy. To encourage the production of eco-friendly aesthetic future demands of renewable shades or colors regarding the environmental awareness towards eco-friendly dyeing and energy save, this article deals on the efficiency of sonic energy in assisting one step extraction and dyeing processes of silk fabric with mixtures of the traditional natural dyes; turmeric, cochineal and indigo powders with different percentages at different $\mathrm{pH}$ values in water acetone cosolvent. It was concluded that the color values with respect to $K / S$, and $L^{*} a^{*} b^{*}$ values were found to be influenced by the $\mathrm{pH}$ values of the dyeing bath with respect to the chemical structure of the used dyes, where a broad variation in shade and color depth was achieved by applying mixtures of these dyes in various combinations, given that both ultrasonic and water acetone co-solvent are environmentally and ecological acceptable for dyeing technology.

\section{REFERENCES}

Aggarwal BB, Kumar A, Bharti AC (2003). Anticancer potential of curcumin: Preclinical and clinical studies. Anticancer Res. 23(1A):363-398.

Al-Amoudi ES, Osman EM (2009). Optimization of Dyeing Performance of an Eco Friendly Natural Dye "Vervain Barks" applied to Silk fabrics at different $\mathrm{pH}$ values. RJTA 13(1):34-45.

Allevi P, Tyman A (1998). Synthesis of carminic acid, the colorant principle of cochineal. J. Chem. Soc. Perkin Trans. 1(3):575-582.

Balasubramanian K (1990). Two Colorful Applications of the PPP Method. Int. J. Quantum Energy 37(4):449-463.

Bechtold T, Turcanu A, Ganglberger E, Geissler S (2003). Natural dyes in modern textile dye houses -how to combine experiences of two centuries to meet the demands of the future?. J. Cleaner Prod. 11(5):499-509.

Cardon D (2007). Natural Dyes: Sources. Tradition, Technology and Science, (Trad. C. Higgitt). London: Archetype.

Christie RM, Mather RR, Wardman RH (2000). The Chemistry of Color Application, Wiley, Blackwell Sci. Oxford.

El-Nagar K, Sanad SH, Mohamed AS, Ramadan A (2005). Mechanical properties and stability to light exposure for dyed Egyptian cotton fabric with natural and synthetic dyes. Polym. Plast. Technol. Eng. 44(7):1269-1279
Ferreira ESB, Alison NH, Quye A (2004). The natural constituents of historical textile dyes. Chem. Soc. Rev. 33(6):329-336.

Garland CE (1993). Color technology in textile chemistry. AATCC, In C. Gultekin (Ed.). pp. 107-112.

Heba FM (2009). Environment and energy efficient dyeing of woollen fabric with sticta coronate. Clean Tech. Environ Policy, DOI 10.1007/s10098-009-0267-7.

Heba FM, Gamal AM (2011). Environmental Assessment of Osage orange Extraction and Its Dyeing Properties on Protein Fabrics. Part II: Dyeing Properties. J. Environ. Sci. Technol. 4(4):395-402.

Heba FM, Heffernan S (2010). Environmental aspects on dyeing silk fabric with sticta coronata lichen using ultrasonic energy and mild mordants. Clean Tech. Environ. Policy, Springer-Verlag, DOI 10.1007/s10098-010-0296-2.

lqbal JM, Ashiq MN (2007). Adsorption of dyes from aqueous solution on activated charcoal. J. Hazard. Mater. 139(1):57-66.

Jayaprakasha GK, Rao JM, Sakariah KK (2002). Improved HPLC for the determination of curcumin, demethoxycurcumin, and bisdemethoxycurcumin. J. Agric. Food Chem. 50(13):3663-3672.

Jayaprakasha GK, Rao JM, Sakariah KK (2005). Chemistry and biological activities of C. longa. Trends Food Sci. Technol. 16(12):533-548.

Jiang H, Timmermann BN, Gang, DR (2006). Use of liquid chromatographyelectrospray ionization tandem mass spectrometry to identify diaryheptanoids in turmeric (Curcuma longa L.) rhizome. J. Chromatogr. A. 1111(1):21-31.

Kamel MM, El-Shishtawy RM, Youssef BM, Mashaly H (2007). Ultrasonic assisted dyeing. IV. Dyeing of cationised cotton with lac natural dye. Dyes Pigm. 73(3):279-284.

Kongkachuichaya $P$, Shitangkoonb A, Chinwongamorna N (2002). Studies on Dyeing of Silk Yarn with Lac Dye: Effects of mordants and dyeing conditions. Sci. Asia. 28:161-166.

Kubelka PI (1948). New contribution to the optics of intensity lightscattering materials-Part I. JOSA. 38:448-451.

Marmion DM (1991). Handbook of US Colorants", Foods, Drugs, Cosmetics and Medical Devices, $3^{\text {rd }}$ edn, John Wiley \& Sons, New York.

Moeyes M (1993). Natural dyeing in Thailand, White Lotus, ISBN $974-$ 8495-92-2, Bangkok, Thailand.

Montazer M, Parvinzadeh M (2004). Colorimetric properties of wool dyed with natural dyes after treatment with ammonia. Color Technol. 120(4):161-166.

Muhammed AR, Soliman A, Khattab M (2008). Solvent effect on the Spectral Properties of neutral red. Chem. Central J. DOI:10.1186/1752-153X-2-19.

Osman EM, El-Ebissy AA, Michaell MN (2009). Characterization and Evaluation of the Levelness Parameters of Natural Dyes on Natural Fabrics. RJTA 13(2):61-68.

Padma VS, Mahanta D, Tiwari SC (2006). Ecofriendly sonicator dyeing of cotton with Rubia cordifolia Linn. Using biomordant. Dyes Pigm. 76(1):207-212.

Roessler A, Crettenand D (2004). Direct electrochemical reduction of vat dyes in a fixed bed of graphite granule. Dyes Pigm. 63(1):29-37.

Roessler A, Jin X (2003). State of the art technologies and new electrochemical methods for the reduction of vat dyes. Dyes Pigm. 59(3):223-235.

Siva R (2007). Status of natural dyes and dye-yielding plants in India. Curr. Sci. 92(7):916-925.

Stankovic I (2004). Curcumin, Chemical and Technical Assessment, $61^{\text {st }}$ JECFA (CTA), (C) FAO, 1(8).

Vajnhandl S, Le Marechal MA (2005). Ultrasound in textile dyeing and the discoloration and mineralization of textile dyes. Dyes Pigm. 65(2):89-101.

Wang YJ, Pan MH, Lin AL, Ho LI., Hsieh YS, Lin JK (1997). Stability of curcumin in buffer solutions and characterization of its degradation products. J. Pharm. Biomed. Anal. 15(12):1867-1876.

www.dow.com/productsafety/.../acetone.

www.madsci.org/.../1060116066.Ch.r.ht 